\title{
Isolation, identification, and complete genome sequence of a bovine adenovirus type 3 from cattle in China
}

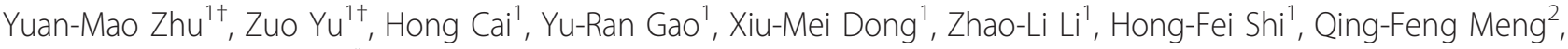 \\ Chuang Lu' ${ }^{1}$ and Fei Xue ${ }^{1 *}$
}

\begin{abstract}
Background: Bovine adenovirus type 3 (BAV-3) belongs to the Mastadenovirus genus of the family Adenoviridae and is involved in respiratory and enteric infections of calves. The isolation of BAV-3 has not been reported prior to this study in China. In 2009, there were many cases in cattle showing similar clinical signs to BAV-3 infection and a virus strain, showing cytopathic effect in Madin-Darby bovine kidney cells, was isolated from a bovine nasal swab collected from feedlot cattle in Heilongjiang Province, China. The isolate was confirmed as a bovine adenovirus type 3 by PCR and immunofluorescence assay, and named as HLJ0955. So far only the complete genome sequence of prototype of BAV-3 WBR-1 strain has been reported. In order to further characterize the Chinese isolate HLJ0955, the complete genome sequence of HLJ0955 was determined.

Results: The size of the genome of the Chinese isolate HL0955 is 34,132 nucleotides in length with a G+C content of 53.6\%. The coding sequences for gene regions of HLJ0955 isolate were similar to the prototype of BAV-3 WBR-1 strain, with 80.0-98.6\% nucleotide and 87.5-98.8\% amino acid identities. The genome of HL0955 strain contains 16 regions and four deletions in inverted terminal repeats, E1B region and E4 region, respectively. The complete genome and DNA binding protein gene based phylogenetic analysis with other adenoviruses were performed and the results showed that HL0955 isolate belonged to BAV-3 and clustered within the Mastadenovirus genus of the family Adenoviridae.

Conclusions: This is the first study to report the isolation and molecular characterization of BAV-3 from cattle in China. The phylogenetic analysis performed in this study supported the use of the DNA binding protein gene of adenovirus as an appropriate subgenomic target for the classification of different genuses of the family Adenoviridae on the molecular basis. Meanwhile, a large-scale pathogen and serological epidemiological investigations for BVA-3 infection might be carried out in cattle in China. This report will be a good beginning for further studies on BAV-3 in China.
\end{abstract}

Keywords: Bovine adenovirus type 3, Cattle, Complete genome, DNA binding protein

\section{Introduction}

Bovine adenovirus type 3 (BAV-3) belongs to the Mastadenovirus genus of the family Adenoviridae and is involved in respiratory and enteric infections of calves [1]. Bovine adenoviruses (BAVs) cause a variety of clinical signs

\footnotetext{
* Correspondence: fxue@hvriac.cn

+ Contributed equally

'Division of Livestock Infectious Diseases, State Key Laboratory of Veterinary Biotechnology, Harbin Veterinary Research Institute of Chinese Academy of Agricultural Sciences, No. 427 Maduan Street, Nan Gang District, Harbin 150001, Heilongjiang Province, PR China

Full list of author information is available at the end of the article
}

including conjunctivitis, pneumonia, diarrhea, and polyarthritis [2,3]. BAVs are classified into ten serotypes [4]. The serotypes of BAV-1, $-2,-3,-9$ and -10 belong to Mastadenovirus genus, and the serotypes of BAV- $-4,-5,-6,-7$, and -8 belong to Atadenovirus genus http://www.ictvdb.org. These ten serotypes are also divided into two groups on the basis of the differences in their biological and serological distinctiveness $[4,5]$. The members of subgroup 1 bovine adenoviruses (BAV-1, -2, -3, and -9) grow well in established bovine cell lines and contain common complement-fixing antigens, which cross-react with the members

\section{() Biomed Central}


of other mastadenoviruses in the complement fixation tests. However, the members of subgroup 2 (BAV-4, -5, $-6,-7,-8$, and -10$)$ do not cross-react with any other mammalian adenovirus in the complement fixation test and can be propagated exclusively in low-passage cultures of calf testicular or thyroid cells $[6,7]$.

BAV-3, a member of subgroup 1 , is considered one of the important respiratory tract pathogens of cattle, particularly newborn calves [8]. Clinical signs include pyrexia, respiratory distress, and nasal and conjunctival discharges. BAV-3 was firstly isolated by Darbyshire and coworkers in Britain [9]. Like other adenoviruses, BAV3 is a nonenveloped icosahedral particle of 75-80 nm in diameter and has a double-stranded linear genomic DNA [10]. The E1, E3, and E4 regions and its complete genome sequence of BAV-3 have been described $[6,11,12]$. Serologic surveys indicated widespread distribution of BAV throughout the world. The detection, isolation or serological evidence of BAV-3 has not been reported in China. However, there were many cases in cattle showing similar clinical signs to BAV-3 infection in China in 2009. Then we made an attempt to isolate the virus with nasal swabs from cattle in Heilongjiang Province, China, and isolated a virus strain using Madin-Darby bovine kidney (MDBK) cell cultures from bovine nasal swabs. The virus isolate was further characterized for some biological properties, partial and the complete genome sequencing for the isolate and phylogenetic analysis.

\section{Results}

\section{BAV-3 isolation and confirmation}

Nasal swabs collected from a group of feedlot cattle with acute respiratory disease were inoculated into cultures of MDBK cells, and the third passage of one specimen caused obvious cytopathic effect (CPE) in MDBK cells. Compared with normal control MDBK cells, the MDBK cells inoculated with the specimen rounded up and cytoplasmic bridges formed after an incubation period of five days (data not shown). The CPE caused by the specimen was similar to that caused by a BAV-3 isolate FSO-213 [13]. The virus isolate was designated as HLJ0955.

Viral genomic DNA was extracted from the culture supernatant inoculated with isolate HLJ0955 and amplified by polymerase chain reaction (PCR) with the specific primers E2Afwd and E2Aseq1 for BAV-3. Fragment consistent with the expected size of $644 \mathrm{bp}$ (base pair) was obtained from the amplification of isolate HLJ0955 (data not shown), which caused typical CPE in MDBK cells. The amplified product was purified, cloned and sequenced. Blast search revealed that the sequence of the amplified fragment was related to BAV-3 with $95 \%$ nucleotide identity.
The immunofluorescence staining of the MDBK cells inoculated with isolate HLJ0955 and control MDBK cells with BAV-3 specific polyclonal antibody was also done. The immunofluorescence was detected in the cytoplasm of MDBK cells after inoculation with isolate HLJ0955, but there was no immunofluorescence in control MDBK cells (data not shown). All of these results demonstrated that the isolate HLJ0955 was BAV-3.

\section{Morphological determination of strain HLJ0955 using electric microscopy}

Typical virions of approximately $75 \mathrm{~nm}$ in diameter were observed in negative-stain preparations of MDBK cells inoculated with the isolate HLJ0955 (Figure 1).

\section{Full-length sequencing of newly isolated HLJ0955 strain}

The complete genome sequence for HLJ0955 was determined. The entire DBP gene sequence in E2A region and the complete genome sequence of HLJ0955 analyzed in this work were deposited in GenBank under following accession number: JN381195. The complete genome of isolate HLJ0955 is 34,132 nucleotides (nt) in length, which is 314 bases shorter than the previously identified BAV-3 strain WBR-1 genome (34,446 nt). The sequence of the Chinese BAV-3 isolate HLJ0955 has a G+C

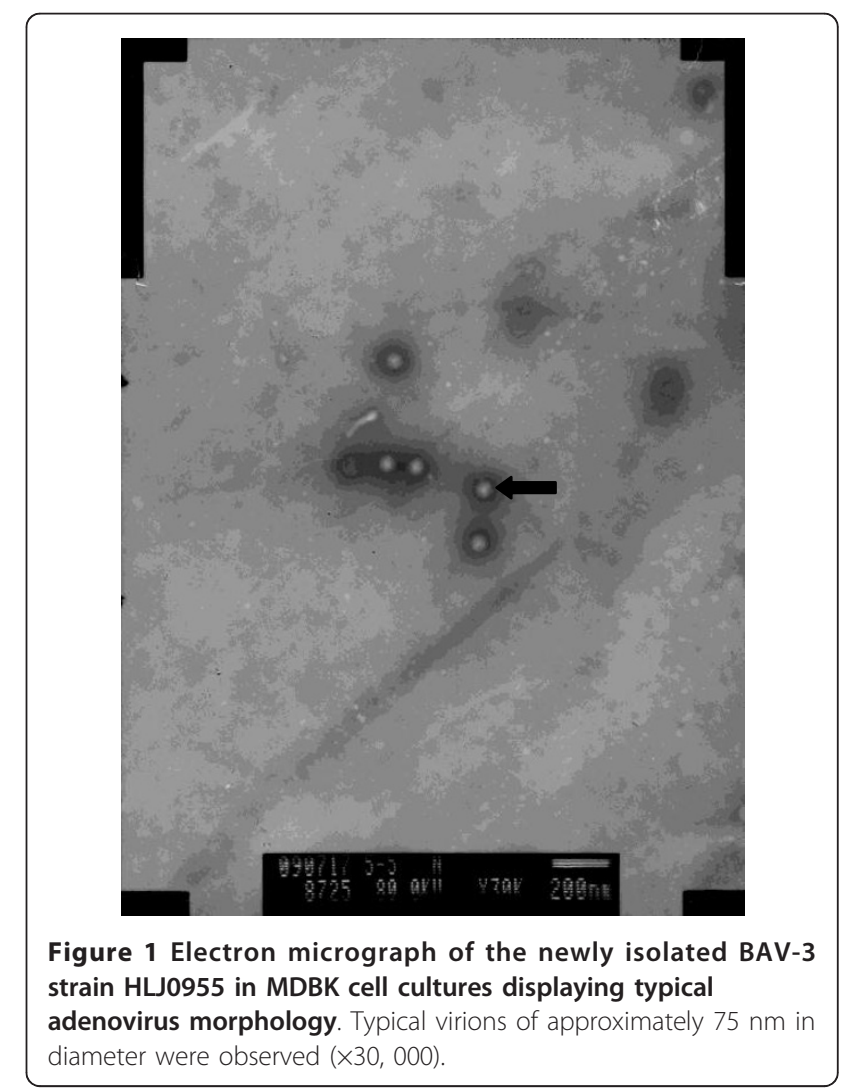


content of $53.6 \%$, which is similar to the $\mathrm{G}+\mathrm{C}$ content of the prototype of BAV-3 WBR-1 strain (54.0\%). The region, name, coding sequence (CDS) and length of genes of Chinese BAV-3 HLJ0955 strain were summarized in Table 1. To further characterize the molecular structure of the HLJ0955 genome and to determine how it is related to the prototype of BAV-3 WBR-1 strain, we compared the nucleotide and putative amino acid sequences of BAV-3 HLJ0955 strain with those of BAV-3 WBR-1 strain retrieved from GenBank (Table 1). The full-length nucleotide homology between HLJ0955 and WBR-1 strains was $70.2 \%$. The CDS for gene regions of HLJ0955 isolate were similar to the prototype of BAV-3 WBR-1 strain, with $80.0-98.6 \%$ nucleotide and 87.5 98.8\% amino acid identities (Table 1).

\section{Adenovirus subtyping using DBP gene}

A phylogenetic tree constructed with the full-length genomes of different adenoviruses showed that HLJ0955 strain clustered with BAV-3 WBR-1 strain with 100\% bootstrap value and also clustered within Mastadenovirus genus with some adenoviruses with $100 \%$ bootstrap value (Figure 2A). The other adenoviruses contained in phylogenetic tree created from the full-length genome data clustered within four different genuses of Adenoviridae family, namely Mastadenovirus, Aviadenovirus, Atadenovirus and Siadenovirus genuses, respectively and their branching patterns were in agreement with presently accepted classification of four different genuses of the family Adenoviridae. Meanwhile, a phylogenetic analysis was performed with the entire coding sequence of DBP

Table 1 Summary of the region, name, CDS and length of genes of Chinese BAV-3 HLJ0955 strain and the nucleotide and putative amino acid identities between HLJ0955 and the prototype of BAV-3 WBR-1 strain

\begin{tabular}{|c|c|c|c|c|c|}
\hline Region & Gene & CDS (HLJ0955) & Gene length (bp) & $\begin{array}{l}\text { Nucleotide identity } \\
\text { with WBR-1 (\%) }\end{array}$ & $\begin{array}{l}\text { Amino acid identity } \\
\text { with WBR-1 (\%) }\end{array}$ \\
\hline \multirow[t]{2}{*}{ ITR } & ITR & $1-85$ & 85 & $N D^{b}$ & ND \\
\hline & & $34048-34132$ & 85 & ND & $\mathrm{ND}$ \\
\hline E1A & $211 R$ & 560-1169, 1277-1302(join) & 636 & 98.6 & 98.6 \\
\hline \multirow[t]{2}{*}{$\mathrm{E} 1 \mathrm{~B}$} & $157 R$ & $1395-1868$ & 474 & 98.0 & 98.1 \\
\hline & $420 \mathrm{R}$ & 1769-3031 & 1263 & 96.4 & 97.9 \\
\hline $\mathrm{plX}$ & plX & $3117-3494$ & 378 & 94.8 & 97.6 \\
\hline IVa2 & IVa2 & 3531-4661(complement $\left.{ }^{a}\right)$ & 1131 & 96.3 & 98.1 \\
\hline \multirow[t]{2}{*}{$\mathrm{E} 2 \mathrm{~B}$} & Pol & 4640-7711(complement) & 3072 & 95.9 & 96.6 \\
\hline & $\mathrm{TP}$ & 7930-9882(complement) & 1953 & 83.9 & 94.8 \\
\hline \multirow[t]{4}{*}{ L1 } & $52 \mathrm{~K}$ & $9912-10907$ & 996 & 96.3 & 97.9 \\
\hline & $\| \mathrm{A}$ & $11022-12737$ & 1716 & 93.0 & 96.8 \\
\hline & III & $12852-14300$ & 1449 & 97.5 & 96.5 \\
\hline & pVII & 14363-14878 & 516 & 97.3 & 97.7 \\
\hline $\mathrm{L} 2$ & $\mathrm{pV}$ & 14995-16266 & 1272 & 94.1 & 87.6 \\
\hline $\mathrm{L} 3$ & $\mathrm{pX}$ & 16393-16632 & 240 & 83.6 & 98.8 \\
\hline L4 & $\mathrm{pVl}$ & $16792-17586$ & 795 & 97.8 & 87.5 \\
\hline \multirow[t]{2}{*}{$\mathrm{L} 5$} & Hexon & $17733-20459$ & 2727 & 80.0 & 94.1 \\
\hline & Protease & 20488-21102 & 615 & 95.7 & 98.0 \\
\hline E2A & DBP & 21219-22517(complement) & 1299 & 96.1 & 98.4 \\
\hline \multirow[t]{3}{*}{ L6 } & $100 K$ & $22544-25096$ & 2553 & 96.5 & 96.0 \\
\hline & $33 K$ & $24729-25553$ & 825 & 96.9 & 92.7 \\
\hline & pVIII & $25732-26382$ & 651 & 97.2 & 97.2 \\
\hline \multirow[t]{2}{*}{ E3 } & $284 \mathrm{R}$ & $26441-27295$ & 855 & 95.3 & 90.9 \\
\hline & $121 R$ & $27306-27671$ & 366 & 97.0 & 97.5 \\
\hline L7 & Fiber & $27898-30828$ & 2931 & 93.4 & 92.7 \\
\hline \multirow[t]{5}{*}{ E4 } & ORF5 & 30906-31565(complement) & 660 & 97.4 & 97.3 \\
\hline & ORF4 & 31504-31935(complement) & 432 & 96.0 & 93.1 \\
\hline & ORF3 & 31957-32763(complement) & 807 & 96.3 & 97.0 \\
\hline & ORF2 & 33028-33237(complement) & 210 & 95.7 & 95.7 \\
\hline & ORF1 & 33250-33675(complement) & 426 & 91.7 & 90.8 \\
\hline
\end{tabular}

\footnotetext{
a represents complimentary strand; ${ }^{b}$ represents "not done"
} 


\section{A The complete genome}

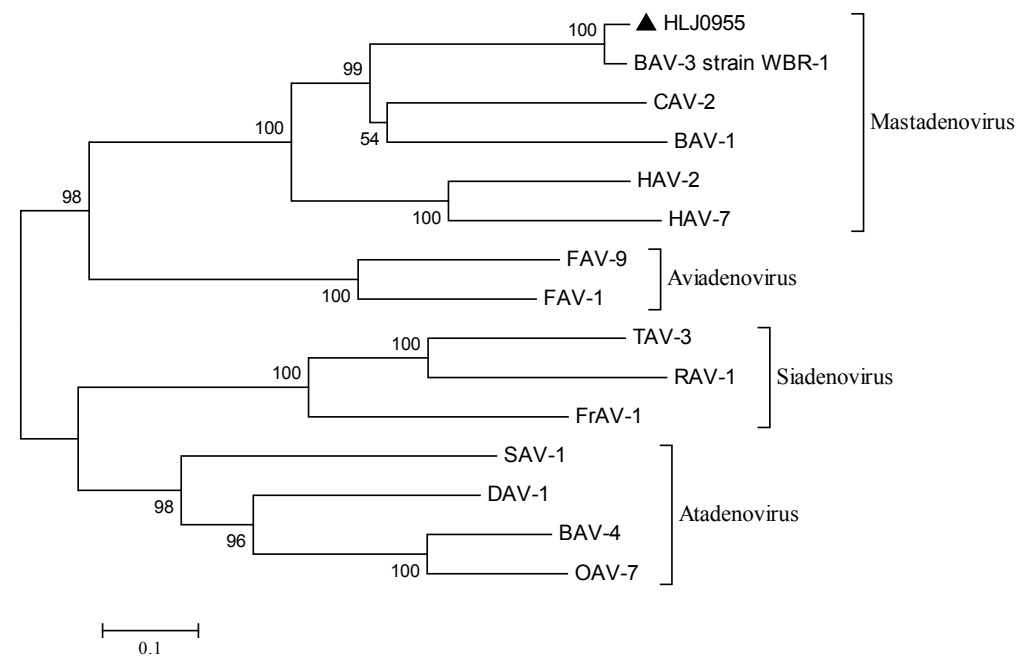

\section{B DBP gene}

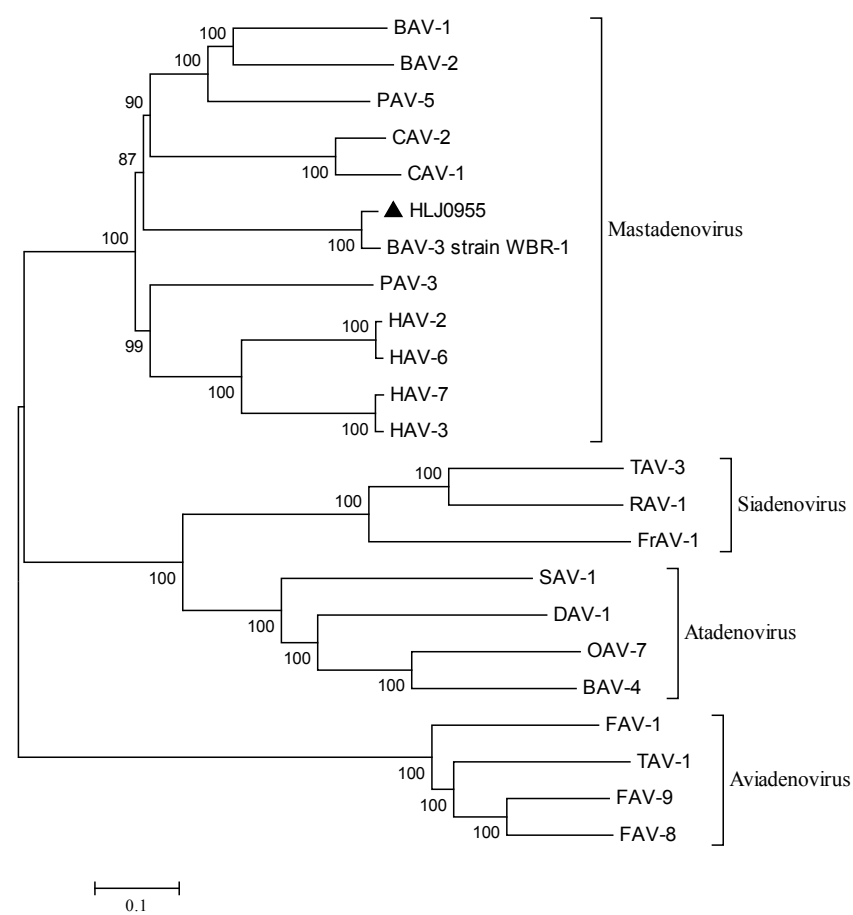

Figure 2 Phylogenetic analysis of the complete genome was created using the complete genome sequence of the HLJ0955 isolate in this work, and 14 BAVs and adenovirus reference strains from other animals or human beings retrieved from GenBank (A, the complete genome). Phylogenetic analysis of the DBP gene was created using the nucleotide sequences of the Chinese BAV-3 isolate HLJ0955 in this work, and 22 BAVs and adenovirus reference strains from other animals or human beings retrieved from GenBank (B, DBP gene). The phylogenetic tree was prepared using the Neighbor-Joining method and bootstrap testing. Numbers over branches indicate the percentage of 1000 bootstrap replicates that support each phylogenetic branch. The GenBank accession numbers of adenovirus reference strains are as follows: BAV-1 (NC_006324), BAV-2 (AF252854), BAV-3 strain WBR-1 (AF030154), BAV-4 (AF036092), canine adenovirus-1 (CAV-1) (AC_000003), CAV-2 (U77082), duck adenovirus-1 (DAV-1) (AC_000004), fowl adenovirus-1 (FAV-1) (AC_000014), FAV-8 (AF083975), FAV-9 (AF083975), frog adenovirus-1 (FrAV-1) (NC_002501), human adenovirus-2 (HAV-2) (AC_000007), HAV-3 (DQ086466), HAV-6 (FJ349096), HAV-7 (AY594256), ovine adenovirus-7 (OAV-7) (U40839), porcine adenovirus-3 (PAV-3) (AF083132), PAV-5 (AF289262), raptor adenovirus-1(RAV-1) (NC_015455), snake adenovirus-1 (SAV1) (DQ106414), turkey adenovirus-1 (TAV-1) (NC_014564), TAV-3 (AC_000016). 
gene in E2A region (Figure 2B). The analysis showed that HLJ0955 strain clustered with BAV-3 WBR-1 strain with $100 \%$ bootstrap value and also clustered within Mastadenovirus genus with some adenoviruses with $100 \%$ bootstrap value. The other adenoviruses contained in phylogenetic tree created from the DBP gene nucleotide data clustered within four different genuses of Adenoviridae family and their branching patterns were also in agreement with presently accepted classification of four different genuses of the family Adenoviridae. These analysis results showed that the phylogenetic tree created from the DBP gene nucleotide data was in agreement with the phylogenetic tree created from the complete genome sequence.

\section{Discussion}

A virus strain, showing cytopathic effect in MDBK cells, was isolated from a bovine nasal swab collected from feedlot cattle in Heilongjiang Province, China in 2009. The isolate was confirmed as a bovine adenovirus type 3 by PCR and immunofluorescence assay, and named as HLJ0955. As well, typical virions were observed in negative-stain preparations of MDBK cells inoculated with the isolate HLJ0955 (Figure 1). To date, only the complete genome sequence of prototype of BAV-3 WBR-1 strain has been reported. In order to further analyze the Chinese BAV-3 isolate HLJ0955, the complete genome sequence for HLJ0955 was determined. Compared with the prototype of BAV-3 WBR-1 strain, the genome of BAV-3 HLJ0955 strain contains 16 regions and four deletions in inverted terminal repeats (ITR), E1B region and E4 region, respectively. The ITR of isolate HLJ0955 is $85 \mathrm{nt}$ in length, which is 110 bases shorter than the previously identified BAV-3 strain WBR-1 ITR (195 nt). A $46 \mathrm{bp}$ deletion occurs in ITR from the left end of the HLJ0955 genome, which is corresponding to the nt 132 to 182 from the left end of the WBR-1 genome. As well, another 85 bp deletion also occurs in ITR from the left end of the HLJ0955 genome, which is corresponding to the nt 34282 to 34366 from the left end of the WBR-1 genome. Whether or not the deletions in ITR of HLJ0955 affect virus replication need further investigations. Interestingly, a $72 \mathrm{bp}$ internal deletion in the left inverted terminal repeat of the bovine adenovirus type 3 mutant BAV3c29 was also found and did not affect virus replication [14]. A 35 bp deletion occurs in E1B region, which is corresponding to the nt 1370 to 1404 from the left end of the WBR-1 genome. The deletion in E1B region did not affect the coding region of E1B product of HLJ0955. The last 145 bp deletion immediately in E4 open reading frame (ORF) 1 region, which is corresponding to the nt 33471 to 33615 from the left end of the WBR-1 genome. Compared with the prototype of BAV-3 WBR-1 strain, the deleted nucleotides of
BAV-3 HLJ0955 strain are totally $311 \mathrm{bp}$. The deletion in E4 ORF1 region caused minor changes of the ORF1 product of HLJ0955. The E4 region of BAV-3 lies near the right end of the genome (nt 30932c to 33950c) and consists of five ORFs [6]. The proteins encoded by the E4 region are involved at several levels of regulation of cellular and viral gene expression, viral DNA replication, late viral assembly, E2 expression, and adeno-associated virus helper function [15-18]. It has been suggested that individual ORFs of the BAV-3 E4 can be deleted and are nonessential for viral replication [19]. But the deletion of HLJ0955 strain in E4 region did not result in any deletion of five ORF products of HLJ0955 strain.

To better understand the genetic relationships and evolution of HLJ0955 strain with other adenoviruses, phylogenetic analysis were performed with the fulllength genomes and entire coding sequence of DBP gene in E2A region of different adenoviruses. The analysis showed that HLJ0955 strain clustered with BAV-3 WBR-1 strain with $100 \%$ bootstrap value and also clustered within Mastadenovirus genus with some adenoviruses with $100 \%$ bootstrap value (Figure $2 \mathrm{~A}$ and $2 \mathrm{~B}$ ). The other adenoviruses contained in phylogenetic tree clustered within four different genuses of Adenoviridae family and their branching patterns were in agreement with presently accepted classification of four different genuses of the family Adenoviridae. These results indicated that the phylogenetic tree created from subgenomic data of the DBP gene nucleotide sequences was in agreement with the phylogenetic tree created from the complete genome sequences. As well, phylogenetic reconstruction with DBP gene nucleotide data of human adenovirus also provided meaningful inferences in molecular characterization of human adenoviruses [20]. The determinations of phylogenetic relationships by comparisons of sequence data play a major role in the classification of viruses within a particular genus in addition to serological tests [6]. The phylogenetic analysis results presented in this study supported the use of the DBP gene of adenovirus as an appropriate subgenomic target for the classification of different genuses of the family Adenoviridae on the molecular basis. These results may provide insight into the molecular properties of HLJ0955 strain and open a new way to further studies.

The isolation of BAV-3 has not been reported prior to this study in China. An important factor with bovine adenovirus isolation is that a fairly large number of serial blind passages of the material is often necessary before a characteristic CPE begins to develop [13]. We have collected numerous nasal swabs from feedlot cattle with acute respiratory disease and finally succeeded to isolate the HLJ0955 strain in 2009. Bovine respiratory disease complex (BRDC) is a major problem for cattle and it continues to cause serious economic losses for 
the global cattle industry. The causes of BRDC are multiple and complex, but the three factors of stress, viral infection and bacterial infection are almost always involved in cases of severe disease. From Autumn in 2008 on, it was reported that a few herds of calves showed acute respiratory disease after a long distance transportation for sales in China. The sick calves were treated with antibiotics, but recovered very slowly and some of them died. Then viral agents were suspected for involvement in the calf pneumonia and bovine parainfluenza virus type 3 and bovine viral diarrhea virus were detected $[21,22]$. However, the viral agents involved in BRDC still need further investigations in China. This is the first report about the detection and isolation of BAV-3 in China. On the basis of this work, a broad pathogen epidemiological investigation of BAV3 might be carried out and serological methods would be established for detecting antibodies against BAV-3 in China. Vaccine for BAV-3 might be developed using the new isolate HLJ0955 of BAV-3. All of these efforts would greatly improve the investigations on BRDC in China. On the other hand, recombinant BAV-3 is being developed as a live vector for animal vaccination and for human gene therapy $[12,23]$. Therefore the BAV-3 strain HLJ0955 might be developed as an appropriate expression vector.

\section{Conclusions}

This is the first study to report the isolation and molecular characterization of BAV-3 from cattle in China. The phylogenetic analysis performed in this study supported the use of the DNA binding protein gene of adenovirus as an appropriate subgenomic target for the classification of different genuses of the family Adenoviridae on the molecular basis. Meanwhile, a large-scale pathogen and serological epidemiological investigations for BVA-3 infection might be carried out in cattle in China. This report will be a good beginning for further studies on BAV-3 in China.

\section{Materials and methods}

\section{Preparation of samples and virus isolation}

Nasal swabs from feedlot cattle with acute respiratory disease were collected from Heilongjiang Province, China in 2009. The swabs were centrifuged for $5 \mathrm{~min}$ at $800 \times \mathrm{g}$ and the supernatant fluids were used for virus isolation. MDBK cells were grown in minimum essential medium (MEM, GIBCO) supplemented with $10 \%$ heat inactivated fetal bovine serum (BIOCHROM AG, German). The supernatants of nasal swabs $(100 \mu \mathrm{l})$ were inoculated into each well of MDBK cells cultured in 24well cell culture plates and incubated for $1 \mathrm{~h}$ at $37^{\circ} \mathrm{C}$. Then the inoculations were discarded and $500 \mu$ l MEM supplemented with $4 \%$ heat inactivated fetal bovine serum were added. The cell cultures were frozen and thawed three times and passaged three to five times at seven days interval. Harvest the cell cultures by freezing and thawing them for three times when CPE appeared in monolayer of MDBK cells. Then the isolates were further identified.

\section{PCR detection and nucleotide sequence analysis}

Oligonucleotide primers for BAV-3 detection and identification were designed from the DNA binding protein (DBP) gene sequence in E2A region of BAV-3 strain WBR-1 (GenBank accession number AF030154). The sequence of two pairs of primers, designed E2Afwd and E2Aseq1, was located in E2A region of BAV-3. The primers E2Afwd (5'GAG ATG GAT GTG AAC AGC GA-3') and E2Aseq1 (5'-ACA TTC TGA TGC TGG TAC TG-3') amplified an approximately 644 bp product from the BAV-3 DNA.

Viral genomic DNA was extracted from $500 \mu \mathrm{l}$ of infected culture supernatant containing $0.2 \mathrm{mg} / \mathrm{ml}$ proteinase K (AMRESCO, USA) and $0.5 \%$ sodium dodecyl sulfate, which was incubated at $37^{\circ} \mathrm{C}$ for two hours. The digested solution was extracted once with phenol and twice with chloroform-isoamyl alcohol (24:1). The extracted DNA was precipitated by the addition of two volumes of absolute ethanol, recovered by centrifugation, and dissolved in $100 \mu \mathrm{l}$ of TE buffer $(10 \mathrm{mM}$ Tris- $\mathrm{HCl}$ (pH 7.4) and 1 mM EDTA). The dissolved DNA was used as a template for PCR. The amplification of viral DNA by PCR was carried out in a total volume of $50 \mu \mathrm{l}$ containing $20 \mathrm{mM}$ Tris- $\mathrm{HCl}$ (pH8.4), $50 \mathrm{mM} \mathrm{KCl}, 3 \mathrm{mM}$ $\mathrm{MgCl}_{2}, 0.5 \mathrm{mM}$ dNTP, 200 pmol of each primer E2Afwd and E2Aseq1, $10 \mu \mathrm{l}$ extracted DNA and 2.5 U EX Taq DNA polymerase (Takara). The reaction was heated in a thermocycle for $3 \mathrm{~min}$ at $93^{\circ} \mathrm{C}$ and then submitted to 30 cycles of amplification. The conditions of amplification were $45 \mathrm{~s}$ at $95^{\circ} \mathrm{C}, 50 \mathrm{~s}$ at $55^{\circ} \mathrm{C}$, and $1 \mathrm{~min}$ at $72^{\circ} \mathrm{C}$. The final extension step was done at $72^{\circ} \mathrm{C}$ for $10 \mathrm{~min}$.

The PCR products were separated by electrophoresis in $1.5 \%$ agarose gel in Tris-acetate EDTA buffer and the expected band was excised and recovered from the agarose gel using the Watson gel extraction kit (Watson, China). The purified PCR product was ligated into the pGEM-T vector (Promega) using T/A cloning, and the competent Escherichia coli strain DH5 $\alpha$ was transformed with the ligation products following the manufacturer's instruction. The positive colonies (three of each sample), screened by blue-white color reaction on $\mathrm{X}$-gal containing plates, were sequenced with the M13+ and M13- sequencing primers. DNA sequencing was performed on an ABI automated A373 sequencer. Sequences were identified using the BLAST search program http://www.ncbi.nlm.nih.gov/blast/Blast.cgi. 


\section{Electron microscope observation}

MDBK cells infected with the virus isolate were harvested by freezing and thawing for three times. One $\mathrm{ml}$ of the harvested cell cultures was centrifuged for $5 \mathrm{~min}$ at $800 \times \mathrm{g}$. The supernatant was transferred into a new eppendorf tube and centrifuged for $10 \mathrm{~min}$ at 13,400 $\times$ g. Then make negative-stain preparations for transmission electron microscope observation. The observed virions were photographed and analyzed.

\section{Identification of the isolate by immunofluorescent assay}

MDBK cell monolayer grown on 96-well cell culture plates was fixed in $80 \%$ chilled acetone for $20 \mathrm{~min}$ about $36 \mathrm{~h}$ after virus inoculation. After washing out excess unbound reagent with phosphate buffered saline (PBS), the fixed cells were incubated with anti-BAV-3 polyclonal antibody conjugated to FITC (Fluorescein isothiocyanate) (VMRD Inc., USA) at $37^{\circ} \mathrm{C}$ for $30 \mathrm{~min}$ in a humid chamber. After washing with PBS, the cells were examined by fluorescence microscope.

\section{Sequence analysis of the complete genome for HLJ0955 isolate and phylogenetic analysis}

To further characterize the Chinese isolate HLJ0955, the complete genome sequence for isolate HLJ0955 was determined. Forty-two primer sets were designed to amplify overlapping regions of the complete BAV-3 strain HLJ0955 genome. The amplified fragments were harvested and sequenced as described for the E2A region. The complete HLJ0955 genome sequence was compiled from overlapping sequences of the HLJ0955 amplicons. Comparative analysis with the BAV-3 strain WBR-1 genome sequence from GenBank was used to identify coding regions, and putative amino acid sequences were created following BLASTX search routines. Nucleotide and putative amino acid sequence alignments were created using the computer program DNAStar (DNAStar Inc., Madison, WI) with BAV-3 strain WBR-1 sequence retrieved from GenBank (Table 1).

Phylogenetic reconstructions for genetic analysis of the Chinese isolate HLJ0955 were compiled using the complete genome sequence for the isolate HLJ0955 and entire nucleotide coding sequence of DBP gene in E2A region (nucleotide 21284c-22582c of BAV-3 strain WBR1 genome). Additional sequences from representative isolates of previously identified BAVs and adenoviruses from other animals or human beings were included into phylogenetic analysis. Nucleotide sequences were aligned using the Clustal W program. Phylogenetic and molecular evolutionary analyses were conducted using MEGA version 4.0 [24]. Bootstrap values were calculated on 1000 replicates of the alignment.

\section{List of Abbreviations}

BAV: bovine adenovirus; BAV-3: bovine adenovirus type 3; bp: base pair BRDC: bovine respiratory disease complex; CDS: coding sequence; CPE: cytopathic effect; DBP: DNA binding protein; FITC: fluorescein isothiocyanate; ITR: inverted terminal repeat; MDBK: Madin-Darby bovine kidney; MEM: minimum essential medium; nt: nucleotide; ORF: open reading frame; PBS: phosphate buffered saline; PCR: polymerase chain reaction.

\section{Acknowledgements}

This work was supported by Special Fund for Agro-scientific Research in the public interest (No. 201003060-04), P.R. China and a grant from Harbin Veterinary Research Institute, the Chinese Academy of Agricultural Sciences (No. 052-2010J).

\section{Author details}

'Division of Livestock Infectious Diseases, State Key Laboratory of Veterinary Biotechnology, Harbin Veterinary Research Institute of Chinese Academy of Agricultural Sciences, No. 427 Maduan Street, Nan Gang District, Harbin 150001, Heilongjiang Province, PR China. 'Department of Ophthalmology, First Affiliated Hospital of Harbin Medical University, Heilongjiang, Harbin, China.

\section{Authors' contributions}

YMZ, and ZY carried out the isolation and identification of the Chinese BAV3 isolate HLJ0955. HC made the negative-stain preparations for HLJ0955. YRG, XMD, and ZLL carried out PCR amplifications, cloning and sequencing for HLJ0955. HFS, and QFM carried out sequence alignment and phylogenetic analysis. CL participated in its design and coordination. FX designed the study and wrote the manuscript. All authors read and approved the final manuscript.

\section{Competing interests}

The authors declare that they have no competing interests.

Received: 21 July 2011 Accepted: 22 December 2011

Published: 22 December 2011

\section{References}

1. Mohanty BS: Comparative study of bovine adenoviruses. Am J Vet Res 1971, 32:1899-1905.

2. Mattson DE: Adenovirus infection in cattle. J Am Vet Med Assoc 1973, 163:894-895.

3. Mattson DE: Naturally occurring infection of calves with a bovine adenovirus. Am J Vet Res 1973, 34:623-629.

4. Bartha A: Proposal for subgrouping of bovine adenoviruses. Acta Vet Acad Sci Hung 1969, 19:319-321.

5. Horner GW, Hunter R, Bartha A, Benkö M: A new subgroup 2 bovine adenovirus proposed as the prototype strain 10. Arch Virol 1989, 109:121-124

6. Reddy PS, Idamakanti N, Zakhartchouk AN, Baxi MK, Lee JB, Pyne C, Babiuk LA, Tikoo SK: Nucleotide sequence, genome organization, and transcription map of bovine adenovirus type 3. J Virol 1998, 72:1394-1402.

7. Li X, Tikoo SK: Genetic organization and sequence analysis of pVIII, fiber and early region 4 of bovine adenovirus type 7. Virus Genes 2002, 25:59-65.

8. Mattson DE, Norman BB, Dunbar JR: Bovine adenovirus type-3 infection in feedlot calves. Am J Vet Res 1988, 49:67-69.

9. Darbyshire JH, Dawson PS, Lamont PH, Ostler DC, Pereira HG: A new adenovirus serotype of bovine origin. J Comp Pathol 1965, 75:327-330

10. Niiyama Y, Igarashi K, Tsukamoto K, Kurokawa T, Sugino Y: Biochemical studies on bovine adenovirus type 3. I. Purification and properties. J Virol 1975, 16:621-633.

11. Lee JB, Baxi MK, Idamakanti N, Reddy PS, Zakhartchouk AN, Pyne C, Babiuk LA, Tikoo SK: Genetic organization and DNA sequence of early region 4 of bovine adenovirus type 3. Virus Genes 1998, 17:99-100.

12. Baxi MK, Babiuk LA, Mehtali M, Tikoo SK: Transcription map and expression of bovine herpesvirus-1 glycoprotein $D$ in early region 4 of bovine adenovirus-3. Virology 1999, 261:143-152.

13. Lehmkuhl HD, Smith MH, Dierks RE: A bovine adenovirus type 3: isolation, characterization, and experimental infection in calves. Arch Virol 1975, 48:39-46. 
14. van Olphen AL, Mittal SK: A 72 bp internal deletion in the left inverted terminal repeat of the bovine adenovirus type 3 genome does not affect virus replication. Intervirology 2002, 45:188-192.

15. Richardson WD, Westphal $\mathrm{H}$ : A cascade of adenovirus early functions is required for expression of adeno-associated virus. Cell 1981, 27:133-141.

16. Halbert DN, Cutt JR, Shenk T: Adenovirus early region 4 encodes functions required for efficient DNA replication, late gene expression, and host cell shut off. J Virol 1985, 56:250-257.

17. Weinberg $\mathrm{DH}$, Ketner $\mathrm{G}$ : Adenoviral early region 4 is required for efficient viral DNA replication and for late gene expression. J Virol 1986, 57:833-838.

18. Huang MM, Hearing P: Adenovirus early region 4 encodes two gene products with redundant effects in lytic infection. J Virol 1989, 63:2605-2615.

19. Baxi MK, Robertson J, Babiuk LA, Tikoo SK: Mutational analysis of early region 4 of bovine adenovirus type 3. Virology 2001, 290:153-163.

20. Bailey A, Mautner V: Phylogenetic relationships among adenovirus serotypes. Virology 1994, 205:438-452.

21. Xue F, Zhu YM, Li J, Zhu LC, Ren XG, Feng JK, Shi HF, Gao YR: Genotyping of bovine viral diarrhea viruses from cattle in China between 2005 and 2008. Vet Micobiol 2010, 143:379-383.

22. Zhu YM, Shi HF, Gao YR, Xin JQ, Liu NH, Xiang WH, Ren XG, Feng JK, Zhao LP, Xue F: Isolation and genetic characterization of bovine parainfluenza virus type 3 from cattle in China. Vet Micobiol 2011, 149:446-451.

23. Baxi MK, Deregt D, Robertson J, Babiuk LA, Schlapp T, Tikoo SK: Recombinant bovine adenovirus type 3 expressing bovine viral diarrhea virus glycoprotein E2 induces an immune response in cotton rats. Virology 2000, 278:234-243.

24. Tamura K, Dudley J, Nei M, Kumar S: MEGA4: Molecular Evolutionary Genetics Analysis (MEGA) software version 4.0. Molecular Biology and Evolution 2007, 24:1596-1599, (Publication PDF at http://www.kumarlab.net/ publications).

doi:10.1186/1743-422X-8-557

Cite this article as: Zhu et al:: Isolation, identification, and complete genome sequence of a bovine adenovirus type 3 from cattle in China. Virology Journal 2011 8:557.

\section{Submit your next manuscript to BioMed Central and take full advantage of:}

- Convenient online submission

- Thorough peer review

- No space constraints or color figure charges

- Immediate publication on acceptance

- Inclusion in PubMed, CAS, Scopus and Google Scholar

- Research which is freely available for redistribution

Submit your manuscript at www.biomedcentral.com/submit
Biomed Central 